\title{
Criticality Analysis of the Elements of the Light Commercial Vehicle Steering Tie-Rod Joint
}

\author{
Dobrivoje Ćatić ${ }^{*}$ - Branislav Jeremić - Zorica Djordjević - Nenad Miloradović \\ University of Kragujevac, Faculty of Mechanical Engineering, Serbia
}

The introduction of the paper gives the basic concepts of Failure Modes, Effects and Criticality Analysis - FMECA. Features of elements of mechanical systems regarding failure intensity demand a special approach of quantitative FMECA. The paper presents this approach, applied to the elements of mechanical systems and used for the design of a software package. Criticality analysis of failure modes of light commercial vehicle's steering tie-rod joint elements was conducted based on the exploitation results and with the use of the previously mentioned method and program. In conclusion, the possibilities of application of the obtained results are presented.

(C) 2011 Journal of Mechanical Engineering. All rights reserved.

Keywords: reliability, FMECA, steering system of a light commercial vehicle, tie-rod joint

\section{INTRODUCTION}

According to the IEC standard [1], Failure Modes and Effects Analysis (FMEA) is a method for analysis of technical systems reliability. FMEA may be defined as a systematic set of data intended for [2] and [3]: identification and assessment of potential product failures and their effects; determination of measures and activities for elimination or reduction of the possibility for failure to occur and documentation of the previous two procedures.

FMEA was developed for USA military purposes as a technique for the assessment of reliability through the determination of effects of different failure modes of technical systems. This method dates from November 9th 1949 , as an official document in a form of an American military standard, denoted as MIL-P 1629 and named as "Procedure for conduction of analysis of modes, effects and acuteness of failures" [3]. Application of FMEA in automotive industry projects followed no sooner than in the second half of the 1980's and it was related with the introduction of quality regulations Q-101 by American Ford Company. Different extensions of FMEA and customizations of the FMEA method for application in automotive industry were conducted within these activities.

FMEA is a procedure for the evaluation of reliability of a technical system that may be applied in all phases of its lifetime [4]. FMEA is generally an inductive method. It is based on the consideration of all potential failures of constitutive parts of the system and effects they have on the system. Criticality Analysis (CA) is a procedure for the evaluation of criticality rating for all constitutive parts, where, by criticality, a relative measure of item failure modes influence on reliable and safe operation of the system is meant. Joint FMEA and CA analysis are called Failure modes, effects and criticality analysis FMECA. According to previous considerations, the application of FMECA based on exploitation data is founded on the assumption that the intensity of all failure modes of system elements is constant, which is valid for electronic systems [5] and [6]. This assumption considerably simplifies the procedure for criticality assessment. However, the application of this methodology in cases when failure intensity is a function of time may lead to distortion of the real picture of elements' criticality. A proposal for the procedure of quantitative FMECA of machine system elements, originating from modification of the existing method, is given in book [7].

Element criticality analysis is extremely important for the systems with serial connection between elements (as in the vehicle steering system), where failure of any element leads to a failure of the entire system. The steering system is one of the vital parts of a motor vehicle complex mechanical system [8]. Together with the braking system and the tires, it has a crucial significance for safety of motor vehicles and people in traffic. Thus, great attention is given to the demands

*Corr. Author's Address: University of Kragujevac, Faculty of Mechanical Engineering,

6 Sestre Janjic Street, 34000 Kragujevac, Serbia, caticd@kg.ac.rs 
that are set before the steering system regarding reliability.

\section{QUANTITATIVE FMECA PROCEDURE FOR MACHINE SYSTEMS' ELEMENTS}

Depending on the requirements and the possibilities for supplying the corresponding data, FMECA may be performed quantitatively and qualitatively [5]. Uniqueness of the machine system elements regarding failure intensity and objective impossibility to determine failure intensity for every possible element failure as the function of time, require special treatment during quantitative FMECA. Quantitative FMECA of machine system elements is defined in four steps:

1. Determination of criticality of failure mode $j$ of element $i$ is to be done by categories of failure effects $k(k=1, \ldots, 4)$, using:

$$
C_{i j}^{(k)}=\frac{\alpha_{i j} \cdot \beta_{i j}^{(k)} \cdot t_{i}}{t_{s r i}},
$$

where $\alpha_{i j}$ is a relative rate (frequency measure) of failure mode $j$ of element $i\left(0 \leq \alpha_{i j} \leq 1, \sum_{j} \alpha_{i j}=1\right)$, $\beta_{i j}^{(k)}$ is conditional probability that failure mode $j$ of element $i$ will cause category $k$ failure effect according to the adopted classification (values are taken from Table 1, according to recommendations from [5] and [6]), $t_{i}$ is operating time of element $i$ and $t_{s r i}$ is mean operating time until failure of element $i$ occurs.

Table 1. Values of conditional probabilities

\begin{tabular}{|l|c|}
\hline $\begin{array}{c}\text { Degree of occurrence of the } k^{\text {th }} \\
\text { failure effect category }\end{array}$ & $\beta_{i j}^{(k)}[-]$ \\
\hline Certain event & 1 \\
\hline Probable event & $0.1 \ldots 1$ \\
\hline Most probably would not happen & $0 \ldots 0.1$ \\
\hline Practically does not happen & 0 \\
\hline
\end{tabular}

The calculated values of $C_{i j}^{(k)}$ are the initial basis for determining other quantitative properties of element criticality. They make it possible to rank element failure modes according to effects in order to evaluate the most critical system's failure modes from the aspect of safety.

2. Determination of failure criticality of element $i$, which causes the $k^{\text {th }}$ category of failure effects:

$$
C_{i}^{(k)}=\sum_{j} C_{i j}^{(k)} .
$$

The calculation of $C_{i}^{(k)}$ enables the isolation of the most important elements whose failures lead to certain categories of effects.

3. Determination of "absolute criticality" of element $i$ according to:

$$
C_{i}=a_{1} C_{i}^{(1)}+a_{2} C_{i}^{(2)}+a_{3} C_{i}^{(3)}+a_{4} C_{i}^{(4)},
$$

where $a_{k}$ is "weight" of the $k^{\text {th }}$ category of effects (values may be determined using subjective evaluation of the effect's "weight" for each case, from the interval between 0 and 1) and $C_{i}^{(k)}$ is the $i^{\text {th }}$ element criticality for the $k^{\text {th }}$ category of effects.

System element criticality rate may be evaluated indirectly, by ranking of acquired values; there is no need for additional complicated analysis when safety and duration aspects are in scope.

4. Determination of criticality of the $k^{\text {th }}$ category of the system's effects, by summation of criticalities of all elements failure modes for the specified effect category:

$$
C_{k}=\sum_{i} \sum_{j} C_{i j}^{(k)} .
$$

Calculated values of $C_{k}$ are statistical indicators of the representation rating of the individual category of effects.

According to the suggested methodology, mean operating time until element failure occurs is one of the basic parameters for determining element criticality. Differences between machine elements in regard to reparability, the percentage of failure occurrence in the system's total operating time, belonging to appropriate structural set, etc., require a special approach in the definition of mean operating time until failure; the calculated element criticalities according to this parameter will then be comparable [7].

Fortran 77 software package was developed for FMECA of machine system elements. This software consists of a routine for calculation of failure modes' criticality and effect categories and their ranking, a subroutine for the transformation of elements of arbitrary array into descending series and a routine for forming of input files. 


\section{TIE-ROD JOINT AS A COMPONENT PART OF MOTOR VEHICLE'S STEERING SYSTEM}

The motor vehicle steering system is a mechanical system that has to meet high demands of reliability [8]. Importance of the motor vehicle steering system for human safety requires a detailed analysis of structural components in view of occurrence of their failure during exploitation.

The steering system of the wheeled vehicle contains two basic subsystems: the steering mechanism (group of steering wheel's column) and the steering linkage (group of tie-rods and steering arms).

In addition to connecting the steering mechanism and the steered wheels, steering linkage has a very important task to provide proper kinematics of the wheel turn. This means that the steering linkage must be completely in accord with the suspension system of the steered wheels, so the motion of the wheels relative to the vehicle frame, does not influence the safety of steering. The previously given task is obtained by designing the linkage system in the form of trapeze.

The steering linkage of a light commercial vehicle's steering system with one-piece cross tierod is presented in Fig. 1 [9].

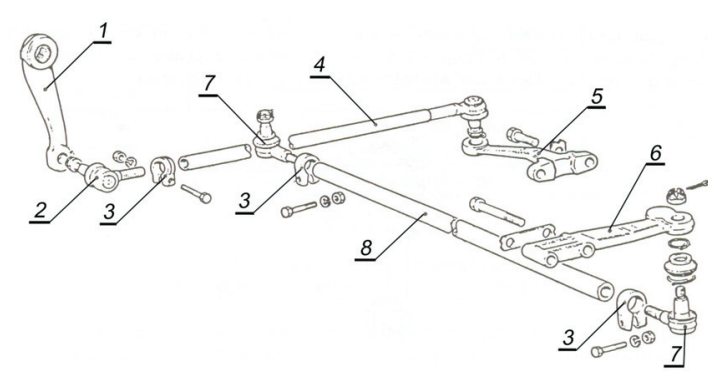

Fig. 1. Steering linkage of light truck's steering system

Torque is transmitted from the output shaft of the steering gear, through the steering arm (1) and the drag arm (consisting of a drag arm joint (2), a clamp (3) and a drag link with joint (4)), to a drag link steering arm (5) on the front left wheel. Drag link steering arm is connected to the wheel spindle by bolts. On the lower side of the left wheel spindle, there is an arm (6) that transfers the force through a cross-link (consisting of joints (7), clamps (3) and cross tube (8)), to the identical link at the right wheel spindle. The front axle, wheel arms (6) and the cross tube form the steering trapeze.

In order to achieve the basic function of the steering system - turning the wheels at a given angle, the linkage mechanisms must never be rigid constructions. Spherical joints are the most convenient links between the elements due to a complex relative motion of the elements of the steering linkage system during turn.

Spherical joints provide mobility in all three planes. There must not be any clearance in the tie-rod joint in order to preserve proper steering kinematics. Cancelation of clearance is achieved by designing the joint cup in two parts, so the upper moving part of the cup presses the ball pin sphere with the help of a spring.

The elements of the tie-rod joint used in the light truck steering systems are shown in Fig. 2.

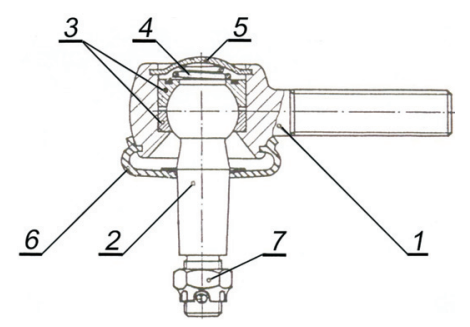

Fig. 2. Tie-rod joint: 1 - Joint's body, 2 - Ball pin, 3 - Cup, 4 - Spring, 5 - Cover, 6 - Sealing cap,

$$
7 \text { - Nut }
$$

By analysis of modes, effects and criticality of failures of the steering system elements built in light commercial vehicles, it has been established that the tie-rod joints are the most critical elements from the aspect of reliability and safety [7].

\section{CRITICALITY DEGREE ANALYSIS OF THE TIE-ROD JOINT'S ELEMENTS}

Due to indisputable importance that the tie-rod joint has in a reliable and safe operation of the motor vehicle steering system, quantitative criticality analysis of this structure was conducted starting at the level of elements. The basis for this analysis was a complex data structure in the form of a table data sheet. The procedure for the acquisition of data needed for quantitative FMECA 
of the tie-rod joint of the light commercial vehicle steering system consisted of the following steps:

1. Structural system division, identification and coding of constitutive elements of the tie-rod joint was done within the structural division of the group of tie-rods and steering arms of light commercial vehicle steering system (Fig. 3);

2. Identification and recording of the most tie-rod joint elements failure modes were performed by forming the fault tree shown in Fig. 4;

3. Determination of relative share of individual element failure modes;

4. A category definition of final failure effects (all failure mode effects of the steering system tie-rod joint elements are classified in four categories: the first category is of the highest rank, and the fourth category is of the lowest rank);
5. Categorization of element failure modes according to effects and determination of conditional probabilities of final effects occurrence;

6. Determination of mean operating time until element failure occurs and

7. The calculation of total operating time of an element (equal for all tie-rod joint elements).

The fault tree of the tie-rod joint presented in Fig. 4 was obtained using symbols for events and logical gates [2]. A rectangle represents the peak or intermediary event in the fault tree, a triangle - primary basic event and a rhomb secondary basic event. Of all logical gates, only a symbol for logical gate OR was used, which produces an output event if one or more input events occur.

Systems and elements of a motor vehicle are loaded with variable loads in the course of time. The total number of load variation cycles

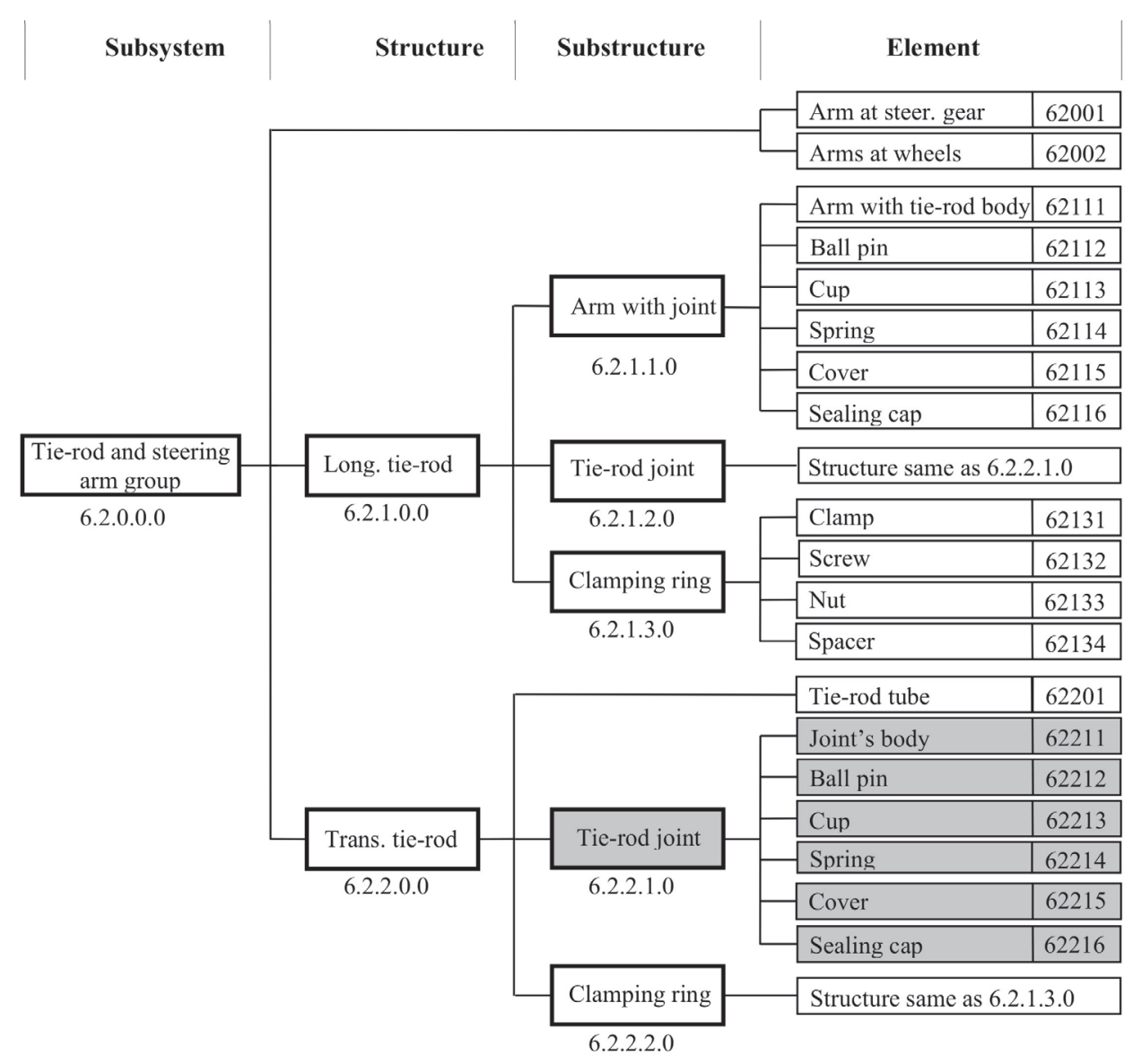

Fig. 3. Division layout of tie-rod and arms group of the light commercial vehicle's steering system 


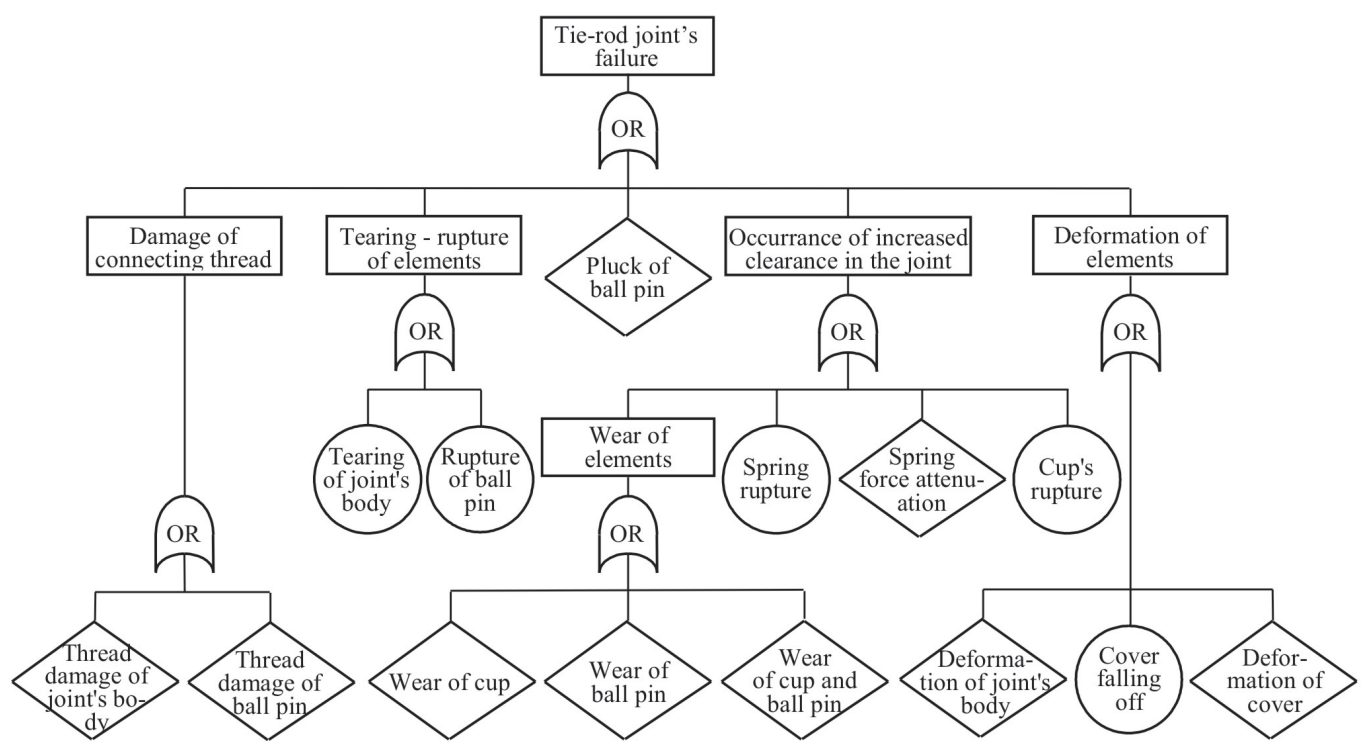

Fig. 4. Independent fault tree of the light commercial vehicle's steering tie-rod joint

is proportional to the distance passed. Thus, time until failure of the most elements of motor vehicles occurs is measured in kilometres of distance passed. Tie-rod joints belong to the group of machine elements whose durability is limited by durability of the critical elements in the structure. Durability of the tie-rod joint is limited by durability of the sliding surfaces of the ball pin and the cup. The estimated mean operation time until failure occurs is $100,000 \mathrm{~km}$ [10].

Elements of the tie-rod joint belong to the group of machine elements in which failure modes occur only in a certain number of them. In that case, it is assumed that the rest of elements that did not fail have the mean time before the failure occurs equal to the mean time until failure of structure occurs. Eq. (5) was used for the calculation of mean time until failure of the tierod joint element occurs in kilometres of distance travelled [7].

$$
s_{s r}=\frac{1}{100} \cdot\left[\sum_{j=1}^{n} p_{j} s_{s r j}+\left(100-\sum_{j=1}^{n} p_{j}\right) \cdot s_{s r s}\right],
$$

where $s_{s r j}$ is mean operation time of the tie-rod joint elements that have failed in the $j^{\text {th }}$ mode, $n$ is the number of different element's failure modes, $p_{j}$ is percentage rate of the $j^{\text {th }}$ failure mode in total number of structure elements failures, $s_{\text {srs }}$ is mean time before structure failure occurs.
Operation time, $t_{i}$, from Eq. (1), is usually expressed in hours. Since criticality is a nondimensional value, it is necessary to express the mean time until element failure occurs in the same units as $t_{i}$. Transformation of mean time until failure of the tie-rod joint elements occur expressed in kilometres of the distance travelled into mean operation time in hours is conducted by the adoption of mean vehicle velocity of $60 \mathrm{~km} / \mathrm{h}$.

Table 2 contains data used to form input files for FMECA.FOR program. To calculate the elements absolute criticality, the following weighting factors of effect categories are adopted: $a_{1}=1 ; a_{2}=0.5 ; a_{3}=0.3 ; a_{4}=0.2$. Weighting factors were adopted by subjective assessment of the experts from the subject area.

Designation $Q$ in Table 2 is for quantity or number of identical elements within the scope of discussed object of analysis.

By processing the acquired data and by using the computer program, output lists are gained for the degree of criticality of the tie rod joint elements failure modes without taking into account the effects (Table 3), the degree of criticality of the tie rod joint elements with taking into account the effects (Table 4), the degree of absolute criticality of the tie rod joint elements (Table 5) and the degree of criticality of final failure effects of the tie rod joint elements (Table $6)$. 
Table 2. Basics of the FMECA procedure for elements of the tie rod joint for light commercial vehicles

\begin{tabular}{|c|c|c|c|c|c|c|c|c|c|c|}
\hline $\begin{array}{l}\text { Element's } \\
\text { name }\end{array}$ & $\begin{array}{l}\text { Elem. } \\
\text { code }\end{array}$ & $\begin{array}{l}Q \\
{[-]}\end{array}$ & Failure mode & $\begin{array}{c}\text { Failure } \\
\text { mode } \\
\text { code }\end{array}$ & $\begin{array}{l}\text { Rel. } \\
\text { rate } \\
\alpha_{i j}[-] \\
\end{array}$ & $\begin{array}{l}\text { Loss } \\
\text { prob. } \\
\beta_{i j}[-]\end{array}$ & $\begin{array}{l}\text { Final } \\
\text { effect }\end{array}$ & $\begin{array}{c}S_{\text {sri }} \\
\times 10^{3} \\
{[\mathrm{~km}]}\end{array}$ & $\begin{array}{c}S_{s r} \\
\times 10^{3} \\
{[\mathrm{~km}]}\end{array}$ & $\begin{array}{c}t_{s r} \\
\times 10^{3} \\
{[\mathrm{~h}]} \\
\end{array}$ \\
\hline $\begin{array}{l}\text { Joint's } \\
\text { body }\end{array}$ & 62211 & 1 & $\begin{array}{l}\text { Deformation } \\
\text { Tearing of joint's body } \\
\text { Thread damage }\end{array}$ & $\begin{array}{l}\text { N.02 } \\
\text { N.06 } \\
\text { N.07 }\end{array}$ & $\begin{array}{c}0.0001 \\
0.0007 \\
0.003\end{array}$ & $\begin{array}{l}0.3 \\
1.0 \\
0.8\end{array}$ & $\begin{array}{l}\text { k.3 } \\
\text { k.1 } \\
\text { k.2 }\end{array}$ & $\begin{array}{l}200 \\
200 \\
100\end{array}$ & 100 & 1.67 \\
\hline Ball pin & 62212 & 1 & $\begin{array}{l}\text { Rupture of ball pin } \\
\text { Thread damage } \\
\text { Pluck of ball pin } \\
\text { Wear }\end{array}$ & $\begin{array}{l}\text { N.06 } \\
\text { N.07 } \\
\text { N.29 } \\
\text { N.77 }\end{array}$ & $\begin{array}{l}0,0007 \\
0.0030 \\
0.0002 \\
0.9961\end{array}$ & $\begin{array}{l}1.0 \\
0.9 \\
1.0 \\
1.0\end{array}$ & $\begin{array}{l}\text { k.1 } \\
\text { k.2 } \\
\text { k.1 } \\
\text { k.3 }\end{array}$ & $\begin{array}{l}200 \\
100 \\
100 \\
100\end{array}$ & 100 & 1.67 \\
\hline Cup & 62213 & 1 & $\begin{array}{l}\text { Cup's rupture } \\
\text { Wear }\end{array}$ & $\begin{array}{l}\text { N.06 } \\
\text { N.77 }\end{array}$ & $\begin{array}{l}0.003 \\
0.997\end{array}$ & $\begin{array}{l}0.7 \\
1.0\end{array}$ & $\begin{array}{l}\text { k.3 } \\
\text { k.3 }\end{array}$ & $\begin{array}{l}150 \\
100\end{array}$ & 100 & 1.67 \\
\hline Spring & 62214 & 1 & $\begin{array}{l}\text { Spring rupture } \\
\text { Spring force attenuation }\end{array}$ & $\begin{array}{l}\text { N.06 } \\
\text { N.12 }\end{array}$ & $\begin{array}{c}0.0008 \\
0.001\end{array}$ & $\begin{array}{l}1.0 \\
0.8\end{array}$ & $\begin{array}{l}\text { k.3 } \\
\text { k.3 }\end{array}$ & $\begin{array}{c}200 \\
20\end{array}$ & 100 & 1.67 \\
\hline Cover & 62215 & 1 & $\begin{array}{l}\text { Deformation } \\
\text { Cover falling off }\end{array}$ & $\begin{array}{l}\text { N.02 } \\
\text { N.29 }\end{array}$ & $\begin{array}{l}0.0002 \\
0.0004\end{array}$ & $\begin{array}{l}0.7 \\
1.0\end{array}$ & $\begin{array}{l}\text { k.3 } \\
\text { k.3 }\end{array}$ & $\begin{array}{l}100 \\
200\end{array}$ & 100 & 1.67 \\
\hline $\begin{array}{l}\text { Sealing } \\
\text { cap }\end{array}$ & 62216 & 1 & $\begin{array}{l}\text { Total rupture } \\
\text { Falling off } \\
\text { Appearance of small rifts }\end{array}$ & $\begin{array}{l}\text { N.06 } \\
\text { N.29 } \\
\text { N.37 }\end{array}$ & $\begin{array}{l}0.002 \\
0.007 \\
0.004\end{array}$ & $\begin{array}{l}1.0 \\
0.9 \\
0.2\end{array}$ & $\begin{array}{l}\text { k.4 } \\
\text { k.4 } \\
\text { k.4 }\end{array}$ & $\begin{array}{c}30 \\
150 \\
20\end{array}$ & 99.89 & 1.66 \\
\hline
\end{tabular}

Table 3. Criticality of elements'failure modes without taking into account the effects

\begin{tabular}{|c|c|l|l|c|c|c|c|c|c|}
\hline No. & Code & $\begin{array}{c}\text { Element's } \\
\text { name }\end{array}$ & \multicolumn{1}{|c|}{ Failure mode } & $\begin{array}{c}\text { Eff. } \\
\text { name }\end{array}$ & $\begin{array}{c}\alpha \\
{[-]}\end{array}$ & $\begin{array}{c}\beta \\
{[-]}\end{array}$ & $\begin{array}{c}t_{s r} \\
{[\mathrm{~h}]}\end{array}$ & $\begin{array}{c}t_{i} \\
{[\mathrm{~h}]}\end{array}$ & $\begin{array}{c}\text { Criticality } \\
C_{i j}^{(k)}[-]\end{array}$ \\
\hline 1 & 62213 & Cup & Wear & $\mathrm{k} .3$ & 0.9970 & 1.0 & $1.67 \mathrm{E}+03$ & 1 & $0.5974 \mathrm{E}-03$ \\
\hline 2 & 62212 & Ball pin & Wear & $\mathrm{k} .3$ & 0.9961 & 1.0 & $1.67 \mathrm{E}+03$ & 1 & $0.5965 \mathrm{E}-03$ \\
\hline 3 & 62216 & Sealing cap & Falling off & $\mathrm{k} .4$ & 0.0070 & 0.9 & $1.66 \mathrm{E}+03$ & 1 & $0.3795 \mathrm{E}-05$ \\
\hline 4 & 62212 & Ball pin & Thread damage & $\mathrm{k} .2$ & 0.0030 & 0.9 & $1.67 \mathrm{E}+03$ & 1 & $0.1617 \mathrm{E}-05$ \\
\hline 5 & 62211 & Joint's body & Thread damage & $\mathrm{k} .2$ & 0.0030 & 0.8 & $1.67 \mathrm{E}+03$ & 1 & $0.1437 \mathrm{E}-05$ \\
\hline 6 & 62213 & Cup & Cup's rupture & $\mathrm{k} .3$ & 0.0030 & 0.7 & $1.67 \mathrm{E}+03$ & 1 & $0.1258 \mathrm{E}-05$ \\
\hline 7 & 62216 & Sealing cap & Total rupture & $\mathrm{k} .4$ & 0.0020 & 1.0 & $1.66 \mathrm{E}+03$ & 1 & $0.1205 \mathrm{E}-05$ \\
\hline 8 & 62216 & Sealing cap & Appear. of small rifts & $\mathrm{k} .4$ & 0.0040 & 0.2 & $1.66 \mathrm{E}+03$ & 1 & $0.4819 \mathrm{E}-06$ \\
\hline 9 & 62214 & Spring & Spring rupture & $\mathrm{k} .3$ & 0.0008 & 1.0 & $1.67 \mathrm{E}+03$ & 1 & $0.4799 \mathrm{E}-06$ \\
\hline 10 & 62214 & Spring & Spring force attenuation & $\mathrm{k} .3$ & 0.0010 & 0.8 & $1.67 \mathrm{E}+03$ & 1 & $0.4799 \mathrm{E}-06$ \\
\hline 11 & 62212 & Ball pin & Rupture of ball pin & $\mathrm{k} .1$ & 0.0007 & 1.0 & $1.67 \mathrm{E}+03$ & 1 & $0.4192 \mathrm{E}-06$ \\
\hline 12 & 62211 & Joint's body & Tearing of joint's body & $\mathrm{k} .1$ & 0.0007 & 1.0 & $1.67 \mathrm{E}+03$ & 1 & $0.4192 \mathrm{E}-06$ \\
\hline 13 & 62215 & Cover & Cover falling off & $\mathrm{k} .3$ & 0.0004 & 1.0 & $1.67 \mathrm{E}+03$ & 1 & $0.2400 \mathrm{E}-06$ \\
\hline 14 & 62212 & Ball pin & Pluck of ball pin & $\mathrm{k} .1$ & 0.0002 & 1.0 & $1.67 \mathrm{E}+03$ & 1 & $0.1198 \mathrm{E}-06$ \\
\hline 15 & 62215 & Cover & Deformation & $\mathrm{k} .3$ & 0.0002 & 0.7 & $1.67 \mathrm{E}+03$ & 1 & $0.8398 \mathrm{E}-07$ \\
\hline 16 & 62211 & Joint's body & Deformation & $\mathrm{k} .3$ & 0.0001 & 0.3 & $1.67 \mathrm{E}+03$ & 1 & $0.1796 \mathrm{E}-07$ \\
\hline
\end{tabular}

The total number of 16 different failure modes was discussed during estimation of criticality degree of the failure mode of tierod joint elements. Based on Table 3, the most critical failure mode of the tie-rod joint elements regardless the effects is wear of the cup and the ball pin. Its criticality is almost 160 times higher than criticality of the next failure mode in the descending order from the Table 3.

Based on criticality degree of the tie-rod joint elements with taking into account the effects (Table 4), it may be seen that, in severe categories of effects, only failure modes of the ball pin and the joint's body occur, but with relatively small 
values of criticality. For effect k.3, the cup and the pin-ball have criticality degree of order $10^{-3}$, while criticality degrees of other elements have orders of $10^{-6}$ and less. Generally, element failure modes with effect k.4, regardless of occurrence, are not authoritative for determining the most critical parts of the observed object.

Table 4. Criticality of elements with taking into account the effects

\begin{tabular}{|c|c|c|c|}
\hline No. & Code & Element's name & $C_{i}^{(k)}[-]$ \\
\hline a) Criticality by effects k.1 \\
\hline 1 & 62212 & Ball pin & $0.5389 \mathrm{E}-06$ \\
\hline 2 & 62211 & Joint's body & $0.4192 \mathrm{E}-06$ \\
\hline b) Criticality by effects k.2 \\
\hline 1 & 62212 & Ball pin & $0.1617 \mathrm{E}-05$ \\
\hline 2 & 62211 & Joint's body & $0.1437 \mathrm{E}-05$ \\
\hline c) Criticality by effects k.3 \\
\hline 1 & 62213 & Cup & $0.5986 \mathrm{E}-03$ \\
\hline 2 & 62212 & Ball pin & $0.5965 \mathrm{E}-03$ \\
\hline 3 & 62214 & Spring & $0.9598 \mathrm{E}-06$ \\
\hline 4 & 62215 & Cover & $0.3239 \mathrm{E}-06$ \\
\hline 5 & 62211 & Joint's body & $0.1796 \mathrm{E}-07$ \\
\hline d) Criticality by effects k.4 \\
\hline 1 & 62216 & Sealing cap & $0.5482 \mathrm{E}-05$ \\
\hline
\end{tabular}

Table 5. Absolute criticality of elements

\begin{tabular}{|c|c|l|c|}
\hline No. & Code & Element's name & $c_{i}[-]$ \\
\hline 1 & 62212 & Ball pin & $0.1803 \mathrm{E}-03$ \\
\hline 2 & 62213 & Cup & $0.1796 \mathrm{E}-03$ \\
\hline 3 & 62211 & Joint's body & $0.1143 \mathrm{E}-05$ \\
\hline 4 & 62216 & Sealing cap & $0.1096 \mathrm{E}-05$ \\
\hline 5 & 62214 & Spring & $0.2879 \mathrm{E}-06$ \\
\hline 6 & 62215 & Cover & $0.9718 \mathrm{E}-07$ \\
\hline
\end{tabular}

Table 6. Criticality of final failure effects

\begin{tabular}{|c|c|c|c|}
\hline No. & Final effect & $C_{k}[-]$ & Rel. crit. [\%] \\
\hline 1 & k.3 & $0.1196 \mathrm{E}-02$ & 99.21 \\
\hline 2 & k.4 & $0.5482 \mathrm{E}-05$ & 0.45 \\
\hline 3 & k.2 & $0.3054 \mathrm{E}-05$ & 0.25 \\
\hline 4 & k.1 & $0.9581 \mathrm{E}-06$ & 0.08 \\
\hline
\end{tabular}

Table 5 contains elements of the tie-rod ranked by absolute criticality. The ball pin and the joint's cup have the highest absolute criticality, followed by the joint's body, the sealing cap, the spring and the cup.

The other way of determining the most critical elements of the steering tie-rod joint is comparative analysis of Tables 6 and 4. In Table 6 , there is obvious predominant occurrence of elements' failure modes with category of effect equal to three. $99.21 \%$ of total sum of elements' criticality are elements' failure modes with third category of effects. Table 4 contains the elements ranked by criticality and by category of effects. For effect k.3, the most critical elements are the cup and the ball pin of the tie-rod joint. Fig. 5 shows distribution of criticality degree of the tierod elements for effect category k.3.
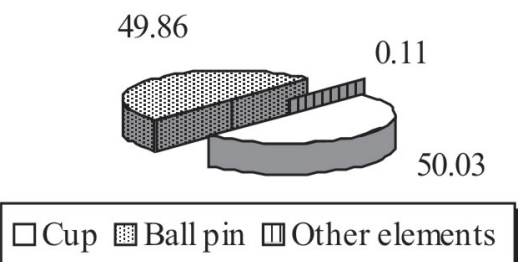

Fig. 5. Distribution of degree of criticality for elements of the steering system's tie rod joint for category of effects $k .3$

As it may be seen in Fig. 5, failure of the tie-rod joint in the largest number of cases appears due to failure of the cup or the ball pin, while only $0.11 \%$ is due to other elements. A similar conclusion may be reached by analysis of absolute criticality of elements (Table 5).

An analysis of failure causes of steering system tie-rod joint elements may give directions for taking appropriate measures for minimization or total elimination of failure causes, or for failure effects reduction. In this way, by using other tools and techniques of the quality system, we get the basis for continuous improvement of the product quality and manufacturing process [11]. Increased clearance in tie-rod joints most frequently occurs in aging period, due to wear of sliding surfaces of the ball pin and the cup. An influence may be exerted on the increase of the mean operating time until the increased clearance in the joint occurs or on the reduction of tie-rod joint criticality by the increase of material or surface layer resistance to wear, by better lubrication and by better protection from the influence of the environment. 


\section{CONCLUSIONS}

A lot of the information necessary for taking measures in order to eliminate detected defects may be obtained by forming the databases of machine system element failures during exploitation and by their processing. Determining critical elements of mechanical systems that limit reliable and safe operation of the system and taking corrective measures in order to reduce the acuteness, present the fastest and the cheapest way to increase reliability and, accordingly, the product's quality.

The use value of FMECA results is in proportion to volume and credibility of the initial data. This points to the need that every company should form an information system for the acquisition and processing of data on errors, defects and failures of company's products. An organised system for data acquisition must provide continuous flow of data, their processing and availability. In order to get complex and credible database on modes, causes, effects and operation periods before failure of mechanical systems or elements occurs, data must be acquired in the design phase, development phase and in product's exploitation.

Parameters of durability (relative frequency of failure occurrence and mean operation time until failure) and parameters of safety (probability of failure effect occurrence - quantitative in nature and failure effect categories - qualitative in nature) have an influence on the criticality of machine system elements in exploitation. As far as quantitative indices are concerned, by analysis of intervals of possible parameter values, it may be concluded that parameters of durability have a dominant influence on the criticality of elements. This is another reason for the criticality of elements, defined according to the given methodology, to be the basis for determination of critical elements that have limiting effect on machine system's reliability.

Generally, the machine system level of reliability can be increased by increasing the reliability of constitutive components or by introducing the parallel connections. Due to space limitations in motor vehicles steering systems, it is not possible to introduce parallel connections, so the only possibility to increase the system's reliability is through the increase of each component's reliability.

\section{REFERENCES}

[1] IEC 60812. (2006). Analysis techniques for system reliability - Procedure for failure mode and effects analysis (FMEA). $2^{\text {nd }}$ ed., Geneva, International Electromechanical Commission.

[2] Lazor, D.J. (1995). Failure mode and effects analysis (FMEA) and fault tree analysis (FTA). Handbook of Reliability Engineering and Management, McGraw-Hill, New York, p. 6.1-6.46.

[3] Stamatis, D.H. (2003). Failure mode and effect analysis. $2^{\text {nd }}$ ed., American Society for Quality, Milwaukee.

[4] Popović, V., Vasić, B., Petrović, M. (2010). The possibility for FMEA method improvement and its implementation into bus life cycle. Strojniški vestnik - Journal of Mechanical Engineering, vol. 56, no. 3, p. 179-185.

[5] Military standard MIL-STD-1629A (1980). Procedures for Performing a Failure Mode. Effects and Criticality Analysis Department of Defense, Washington.

[6] Mtain Inc. Reliability, maintainability, logistics support, engineering services, reliability failure modes, effects and criticality analysis, from http://www.mtain.com/relia/relfmeca. htm, accessed on 2010-06-08.

[7] Ćatić, D. (2005). Development and application of reliability theory methods, Faculty of Mechanical Engineering, Kragujevac.

[8] Janićijević, N., Janković, D., Todorović, J. (1998). Design of motor vehicles. Faculty of Mechanical Engineering, Belgrade.

[9] Service manuals. (1991). Zastava Iveco trucks, Kragujevac.

[10]Ćatić, D., Krstić, B., Miloradović, D. (2009). Determination of reliability of motor vehicle's steering system tie-rod joint. Journal of the Balkan Tribological Association, vol. 15, no. 3, p. 309-322.

[11] Soković, M., Jovanović, J., Krivokapić, Z., Vujović, A. (2009). Basic quality tools in continuous improvement process. Strojniški vestnik - Journal of Mechanical Engineering, vol. 55 , no. 5 , p. 333-341. 